\section{STAIRWAY TO CAREER SUCCESS}

The Denplan Stairway Programme is a structured development programme designed to encompass professional education and development in a relevant and practical format.

In 2010 the programme was established at the University of Birmingham and it has now been recognised by the Faculty of General Dental Practice (UK) (FGDP[UK]).
Members can accumulate 20 credits towards the MSc in Primary Dental Care at Birmingham University and dentists achieving the Denplan Stairway Award can claim 20 credits towards Stage 2 of the FGDP(UK)'s 'Career Pathway' (ten clinical plus ten 'other' credits).

Each unit on the Stairway Programme comprises a study day and practice project on clinical and practice management aspects of running a practice.

Reader response number 58

\section{RELIABLE, CERTIFIED AIR COMPRESSORS}

DentalAir.com air compressors offer maximum reliability and minimum noise levels. All machines are oil free for increased safety and are available for purchase with an optional service and support agreement.

DentalAir.com also offers a low cost lease rental package which includes full servicing and support.

Dental Air have recently been certified to ISO 9001 quality management standards and will provide expert non-obligation advice and full on-site surveys and maintenance anywhere on the UK mainland. Their specialists offer advice on anything from equipment care to the supply of the latest oil-free piston and

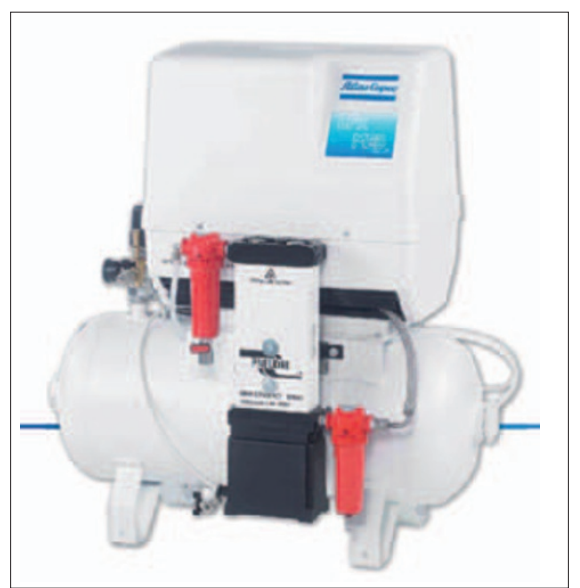

scroll compressors. Dental Air's team of experienced technicians also offer Lunch and Learn sessions on their range of clean air equipment at your practice.

Reader response number 59

\title{
DASH FOR WHITENING KITS
}

Dash is a chairside whitening system which includes everything the clinician needs in one all-inclusive kit. The unique 30\% hydrogen peroxide whitening gel requires no syringe to syringe mixing or refrigeration making it easy to use and store at your practice.

The kit also includes easy-to-follow step-by-step directions which will help you to make isolation and application clear, quick and easy. Included in the pack is a syringe of relief ACP that combines chemical sensitive relief (KNO3) and long term relief of ACP and fluoride.

Dash is available from The Dental Directory for $£ 45$ per kit; just quote product code PGD 060 when ordering. Reader response number 60

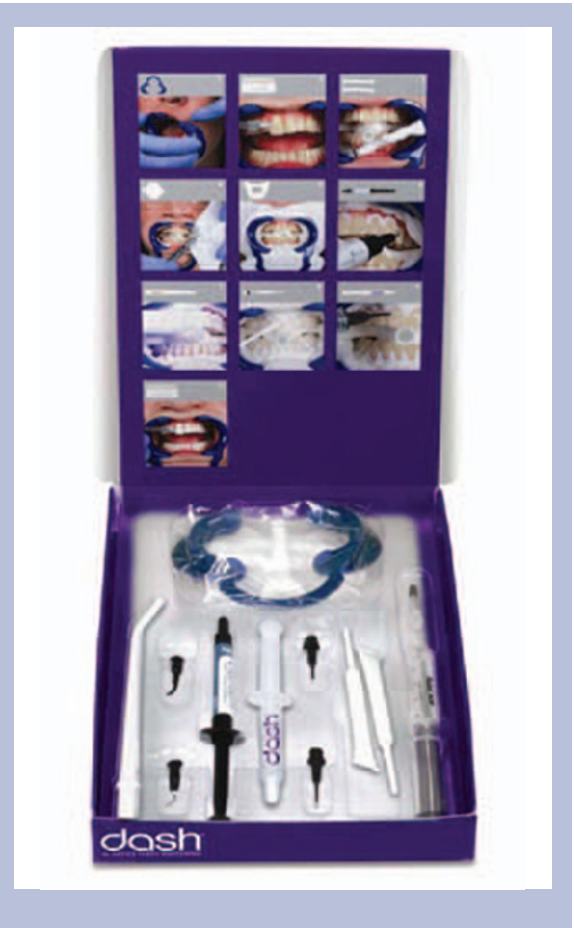

